\title{
Aggregated model of ttf with utaut 2 in an employment website context
}

\author{
Kuo-Yu Huang ${ }^{1}$, Yea-Ru Chuang ${ }^{2}$ \\ ${ }^{I}$ Graduate Institute of Business Administration, College of Management, Fu Jen Catholic \\ University \\ ${ }^{2}$ Department of Information Management, College of Management, Fu Jen Catholic University
}

Abstract: This study applied partial least squares (PLS) path modeling for quantifying and identifying the determinants of job seekers' acceptance and use of employment websites (EWs) by using an aggregate model that applied task-technology fit (TTF), consumer acceptance and use of information technology (UTAUT2). We propose that the most crucial constructs explaining EW adoption are habit, behavioral intention, performance expectancy, and facilitating conditions. This study verified that a job seeker's habits were a major predictor of intention and usage of EWs involving web-based technology and occasional usage. Thus, when job seekers perceive that their task is to fit the technology, they recognize the value of using the technology and use it habitually. 


\section{Introduction}

Employment websites (EWs) are considered the most popular websites for online recruitment (Nikolaou, 2014). The extensiveness, efficacy, and employment rates (Kim, Chun, Kwak, \& Nam, 2014) of EWs are substantially higher than the other e-recruiting websites. Prior studies that have identified a common key determinant: performance expectancy (PE) that influence the use of EWs are limited (Laumer, Eckhardt, \& Trunk, 2010; Lin, 2010; Tong, 2009).

The aim of the present study was to provide a comprehensive insight into the decision factors affecting the adoption of EWs. We established the direct effects of beliefs, affects, and technology characteristics (TECs) on EW adoption behavior by developing a research model that integrates the task-technology fit (TTF) model (Goodhue \& Thompson, 1995), consumer acceptance and use of information technology (UTAUT2) (Venkatesh, Thong, \& $\mathrm{Xu}, 2012$ ). We propose the latest acceptance and use of technology model, the UTAUT2, to examine EWs in the consumer technology acceptance context.

\section{Research questions and hypotheses}

\section{$2.1 \mathrm{TTF}$}

The TTF model was developed by Goodhue and Thompson (1995) and is a reduced model that is based on the technology-to-performance chain (TPC), which Goodhue and Thompson (1995) derived from the theory of cognitive fit. They defined TTF as "the degree to which a technology assists an individual in her or his portfolio of tasks" (p. 216).

Job searching is not a routine daily task, and a job offer or receipt requires that the conditions of both the recruiter and candidate match, rather than a unilateral decision to engage in an employment relationship. These aspects meet the nonroutineness and interdependence requirements of the task characteristics (TASs) of TTF. Job searching was measured using Blau's 12 behavioral items scale (Blau, 1994).

The information systems (ISs) used by each respondent and the respective departments of the respondents were the two dimensions of TECs (Goodhue and Thompson, 1995). The main technical features leading to useful EWs that have been proposed by different researchers include the number of vacancies, matching productivity, search ability, resume production, and resume remanufacturing (Brenčič, 2014; Brenčič \& Norris, 2009; Jansen, Jansen, \& Spink, 2005; Selden \& Orenstein, 2011). Therefore, the hypotheses are as follows:

H1: TASs positively affect the perceived TTF in EWs.

H2: TECs positively affect the perceived TTF in EWs.

Dishaw and Strong (1999) integrated TTF with the technology acceptance model (TAM), and because TTF assesses functionality and the TAM assesses attitude, the two can be merged to provide a more comprehensive understanding. The UTAUT2 model is the extension of the TAM and incorporates the consumer's personal traits (Venkatesh et al., 
2012); through a combination of TTF and the UTAUT2, the cognitive factors reported from investigations involving EWs can provide new information.

TTF is a streamlined model derived from the TPC model (Goodhue \& Thompson, 1995, p. 217). Except for the direct impact of TTF on performance, the impact of TTF on use in the TPC is indicated through the link between TTF and beliefs concerning the consequences of using a system. The antecedents of use are derived from other theories relating to attitudes (beliefs or affects) and behavior. The precursors of use (e.g., the consequences of use, affect toward use, social norms, habits (HBs), and FCs) lead to a person's decision whether to use ISs in the TPC model. In the present study, the PE, effort expectancy (EE), SI, FCs, hedonic motivation (HM), HB, and all the precursors of behavioral intention (BI) and use behavior (UB) in the UTAUT2 model were therefore hypothesized to be the precursors of use in our proposed research model (the Figure 1). Accordingly, the hypotheses are as follows:

H3: Perceived TTF positively affects the PE in EWs.

H4a: Perceived TTF positively affects the EE in EWs.

H4b: Perceived TTF positively affects the SI in EWs.

H4c: Perceived TTF positively affects the FCs in EWs.

H4d: Perceived TTF positively affects the HM in EWs.

H4e: Perceived TTF positively affects the HB in EWs.

Additionally, EWs are consumer-oriented ISs (Maurer \& Liu, 2007), and most job seekers are registered as members in EWs free of charge (Lin, 2010); therefore, the present study omitted the antecedent of BI and "price value" in the UTAUT2 model. 



\subsection{UTAUT2}

Venkatesh et al. (2003) proposed a UTAUT model that was compiled from eight models and theories that presents a more comprehensive understanding of the acceptance process compared with any previous individual models. These eight models and theories are the theory of reasoned action, TAM, motivation model, theory of planned behavior (TPB), combined-TAM-TPB, model of personal computer utilization, innovation diffusion theory, and social cognitive theory. The UTAUT states that there are three direct determinants of intention to use (PE, EE, and SI) and two direct determinants of UB (intention and FCs). Although the UTAUT provides an excellent and detailed model for acceptance and use of technology, it has some limitations (Negahban \& Chung, 2014, p.76). Venkatesh et al. (2012) therefore developed the UTAUT2 and added HM, price value, and HB to explain the model of acceptance and use of consumer technology and adjust it to the consumer technology acceptance context. The UTAUT2 incorporates three additional key constructs, positing that HM, price value, and HB also affect BI and UB directly or indirectly.

$\mathrm{PE}$ is the degree to which a person believes that using a system will help him or her to improve their job performance (Venkatesh et al., 2003). E-recruiting can help job seekers to shorten job search durations, reduce waiting time costs, and achieve transfers more quickly (Maurer \& Liu, 2007). Therefore, the present paper posits the following:

H5: The impact of PE on BI is positive in EWs.

EE is defined as the degree of ease associated with the use of a system (Venkatesh et al., 2003), which involves the "perceived ease of use," "complexity," and "simplicity" concepts. EWs in which the postings are presented in the form of a list, and in which access to the postings is easy and cheap, improve users' perception of usefulness (Brenčič, 2014). Therefore, we hypothesize the following:

H6: The impact of EE on BI is positive in EWs.

The SI of this study is defined as the degree to which a person perceives that crucial people believe that he or she should use EWs (Venkatesh et al., 2003). The effects of SI on usage intentions have significantly influenced studies in past decades (Venkatesh \& Davis, 2000). Therefore, job seekers who wish to conform to the expectations of crucial people anticipate receiving and using EWs. Therefore, we hypothesize the following:

H7: The impact of SI on BI is positive in EWs.

The FCs in the present paper are defined as the degree to which a person believes that an organizational and technological infrastructure exists to support the use of EWs (Venkatesh et al., 2003). A previous study indicated that FCs relating to the intention of younger students to use EWs exert a significant, positive impact on intention to use EWs (Laumer et al., 2010). Therefore, we hypothesize the following:

H8a: The impact of FCs on BI is positive in EWs.

H8b: The impact of FCs on UB is positive in EWs.

$\mathrm{HM}$ is defined as the fun or pleasure derived from using technology, and it has been shown to play a critical role in determining consumer technology acceptance and use (Brown \& 
Venkatesh, 2005). Empirical studies on HM have indicated that it is a particularly critical motivator for current consumers regarding technology acceptance and use (Brown, Venkatesh, \& Hoehle, 2015; Venkatesh et al., 2012). Therefore, we hypothesize the following:

H9: The impact of HM on BI is positive in EWs.

HB is defined as the extent to which people tend to perform behavior automatically because of learning (Limayem, Hirt, \& Cheung, 2007), whereas Kim and Malhotra (2005) equate HB with automaticity. In IS studies, such HB (conceptualized as sticky) has been found to directly influence technology acceptance and use (e.g., Baptista \& Oliveira, 2015; Venkatesh \& Agarwal, 2006; Venkatesh et al., 2012). Therefore, we hypothesize the following:

H10a: The impact of HB on BI is positive in EWs.

H10b: The impact of HB on UB is positive in EWs.

This is consistent with all the models that draw on psychological theories, which argue that individual behavior is predictable and influenced by individual intention $(\mathrm{Yu}, 2012)$. UTAUT and UTAUT2 empirical findings support that BI substantially influences technology use (e.g., Baptista \& Oliveira, 2015; Venkatesh et al., 2003; Venkatesh et al., 2012). Therefore, we hypothesize the following:

H11: The impact of BI on UB is positive in EWs.

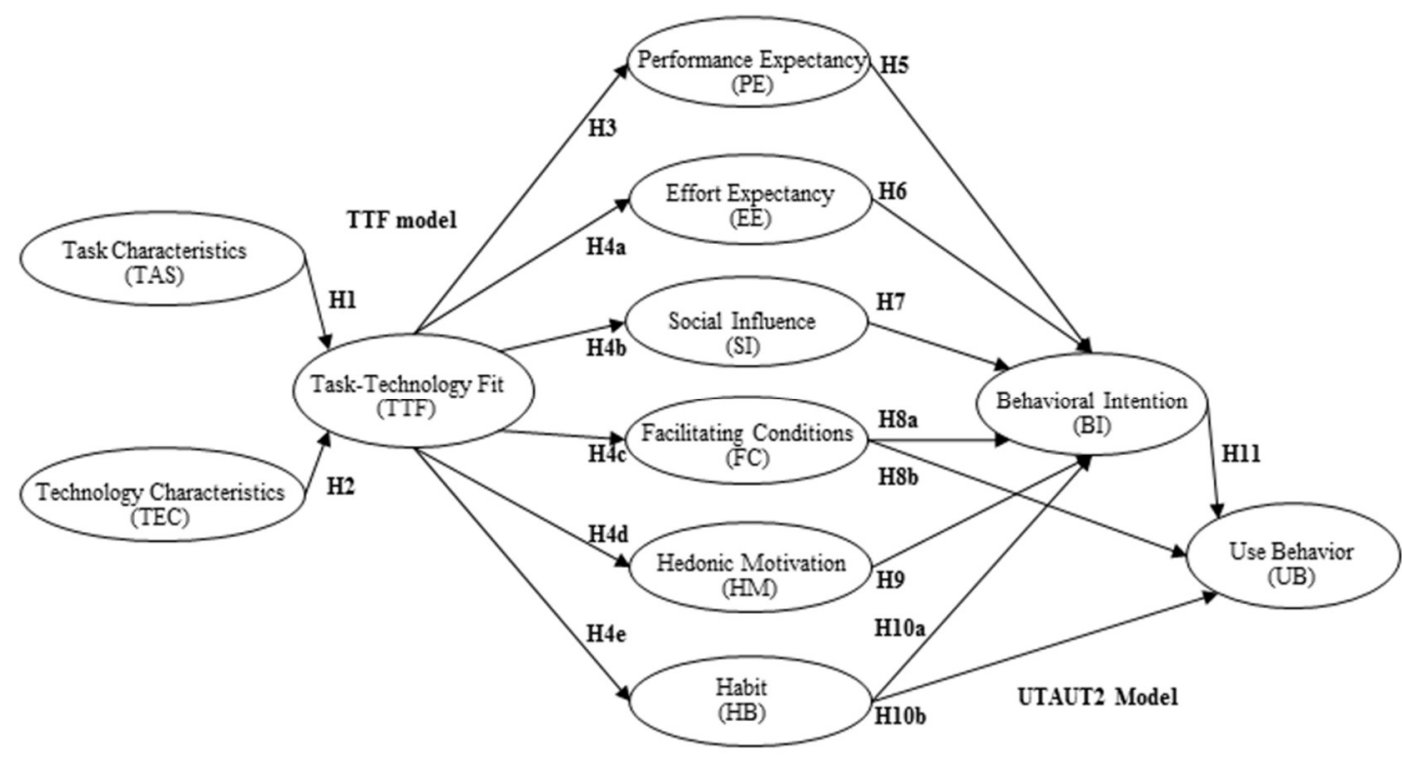

Figure 1. Proposed research model. 


\section{METHODS}

\subsection{Study content and sample}

A survey method was constructed and validated before use to test the research model and its hypotheses. Initially, a questionnaire pretest was conducted using 50 volunteers who had experience using EWs. Respondents were asked to assess logical consistencies, the sequence of items, and the questionnaire format. The participants in the survey were job seekers with EW experience in employment services who were offered by five public employment centers located in Taiwan. The data were collected over a 3-month period in 2015, during which 1,250 job seekers were randomly assigned to complete a paper-and-pencil questionnaire. Of the 962 questionnaires eventually collected, 77 were incomplete. Therefore, only 885 questionnaires were analyzed. Participation in the survey was anonymous and voluntary. Anonymity and confidentiality ensured that participants' responses to a paper-based survey would not affect the selection decisions. The survey questionnaire was translated from English to Chinese and was checked by a second author who is fluent in both English and Chinese; back translation was also employed. The questionnaire covered demographics and general information, resulting in a total of 40 items. Demographic information on the respondents is provided in Table 1. 

Table 1. Demographic characteristics of respondents $(n=885)$

\begin{tabular}{|c|c|c|}
\hline Demographic characteristics & Frequency & $\%$ \\
\hline \multicolumn{3}{|l|}{ Gender } \\
\hline Female & 447 & 51 \\
\hline Male & 438 & 49 \\
\hline \multicolumn{3}{|l|}{ Whether the employment } \\
\hline Employed & 457 & 52 \\
\hline Unemployed & 428 & 48 \\
\hline \multicolumn{3}{|l|}{ Age } \\
\hline $15 \sim 20$ & 48 & 5 \\
\hline $21 \sim 30$ & 324 & 37 \\
\hline $31 \sim 40$ & 269 & 30 \\
\hline $41 \sim 45$ & 112 & 13 \\
\hline $46 \sim 55$ & 121 & 14 \\
\hline $56 \sim 65$ & 11 & 1 \\
\hline \multicolumn{3}{|l|}{ Education } \\
\hline Junior high school or below & 23 & 3 \\
\hline High school & 181 & 20 \\
\hline Junior college & 153 & 17 \\
\hline University & 427 & 48 \\
\hline Graduate school or above & 101 & 11 \\
\hline \multicolumn{3}{|l|}{ Search intensity } \\
\hline $1 \sim N /$ day & 391 & 44 \\
\hline $1 \sim 5 /$ week & 289 & 32 \\
\hline $1 \sim 3 / 1$-month & 80 & 9 \\
\hline $1 / 2$-month & 15 & 2 \\
\hline $1 / 3$-month & 51 & 6 \\
\hline 1 / over 3-month & 59 & 7 \\
\hline \multicolumn{3}{|l|}{ Number of Employment Websites used } \\
\hline Only 1 private EW & 163 & 18 \\
\hline $2 \sim \mathrm{N}$ private $\mathrm{EWs}$ & 328 & 37 \\
\hline Only $1 \sim \mathrm{N}$ public EWs & 17 & 2 \\
\hline $2 \sim \mathrm{N}$ private or public EWs & 377 & 43 \\
\hline
\end{tabular}





\subsection{Measures of Research Variables}

The questionnaire consisted of 34 Likert-type items (ranging from $1=$ strongly disagree to 7 $=$ strongly agree) to measure the constructs in the research model, as derived from the literature. TASs were measured according to four items, which were originally adopted by Blau (1994). TECs were measured according to four items (number of vacancies, matching productivity, search ability, resume production, and resume remanufacturing), which were adopted from the main technical features of EWs proposed by prior studies (Brenčič, 2014; Brenčič \& Norris, 2009; Jansen et al., 2005; Selden \& Orenstein, 2011). We categorized TASs and TECs as formative constructs because they were described and defined according to four items to avoid committing a type I measurement perspective error (Diamantopoulos \& Siguaw, 2006). TTF was evaluated using a three-item scale taken from Lu and Yang (2014).

The measurement items for PE, EE, SI, FCs, HM, HB, BI, and UB were adopted from Venkatesh et al., (2012). PE was assessed using the same three-item scale used by Venkatesh et al. (2012). Likewise, EE was measured according to four items, SI was measured according to three items, HM was measured according to three items, HB was measured according to three items, BI was measured according to three items, and FCs were measured according to three items. Minor wording modifications were made according to e-recruitment service content. UB was measured according to a single item aggregated from a previous study's questionnaire item, "Choose your usage frequency for using the employment websites." The UB construct measurement was sufficiently narrow or unambiguous to the respondent and a single item being "unambiguous" and "concrete" (Bergkvist, 2015). Therefore, a single-item questionnaire can be as effective as a multi-item scale, and the reliability of Cronbach's $\alpha$ of UB is both unknown and unknowable.

\section{RESULTS}

Partial least squares (PLS) regression may overcome the collinearity problem, it requires less computation and reaches its minimal mean square error with a smaller number of factors (Polat \& Gunay, 2015). Meanwhile PLS path modeling was applied for confirmatory factor analysis because it is sufficient for a model with both reflective and formative constructs (Lu \& Yang, 2014, p. 328).

We first analyzed the measurement model to evaluate its reliability and validity; we then used SmartPLS 2.0 to perform path analysis and test the research hypotheses. The means, standard deviation, and correlations among constructs are displayed in Table 2. 
Table 2. Means, standard deviation, correlations, and AVE of constructs

\begin{tabular}{ccccccccccc}
\hline Construct & 1. TASs & 2. TECs & 3.TTF & $4 . \mathrm{PE}$ & $5 . \mathrm{EE}$ & $6 . \mathrm{SI}$ & $7 . \mathrm{FCs}$ & $8 . \mathrm{HM}$ & $9 . \mathrm{HB}$ & $10 . \mathrm{BI}$ \\
Mean & 5.85 & 4.96 & 4.87 & 4.90 & 5.30 & 4.75 & 5.43 & 4.67 & 5.26 & 5.43 \\
SD & 1.48 & 1.51 & 1.50 & 1.49 & 1.33 & 1.53 & 1.41 & 1.58 & 1.56 & 1.53 \\
AVE & $---\mathrm{a}$ & --- & 0.82 & 0.89 & 0.8 & 0.9 & 0.72 & 0.85 & 0.84 & 0.83 \\
\hline 1.TASs & N/A & & & & & & & & & \\
2.TECs & 0.52 & N/A & & & & & & & & \\
3.TTF & 0.53 & 0.77 & $0.91 \mathrm{~b}$ & & & & & & & \\
4.PE & 0.50 & 0.74 & 0.78 & 0.94 & & & & & & \\
5.EE & 0.57 & 0.62 & 0.63 & 0.61 & 0.89 & & & & & \\
6.SI & 0.46 & 0.58 & 0.57 & 0.60 & 0.58 & 0.95 & & & & \\
7.FCs & 0.45 & 0.55 & 0.52 & 0.51 & 0.65 & 0.56 & 0.85 & & & \\
8.HM & 0.39 & 0.57 & 0.62 & 0.60 & 0.61 & 0.65 & 0.60 & 0.92 & & \\
9.HB & 0.55 & 0.59 & 0.63 & 0.71 & 0.64 & 0.66 & 0.61 & 0.62 & 0.92 & \\
10.BI & 0.55 & 0.61 & 0.66 & 0.73 & 0.65 & 0.62 & 0.66 & 0.61 & 0.78 & 0.91 \\
\hline
\end{tabular}

Notes: a Assessing construct validity in terms of convergent and discriminant validity is not meaningful for formative constructs (Hair, Hult, Ringle, \& Sarstedt, 2013).

b Diagonals (bold) represent the square root of the AVE between the constructs. Other entries represent the correlation among constructs.

\subsection{Assessing Validity and Reliability}

Table 3 provides the results of factor loading, Cronbach's $\alpha$, composite reliability, and average variance extracted (AVE) from the constructs. The internal reliability of the measurement model was tested using Cronbach's $\alpha$. As shown in Table 3, all of the Cronbach's $\alpha$ values ranged from 0.80 to 0.94 , which were higher than the minimum cutoff score of 0.70 (Nunnally, 1978). The convergent validity of constructs was assessed by examining the factor loadings of each item as well as the composite reliabilities and variances extracted from latent constructs. First, the standardized factor loadings were significant $(\mathrm{p}<.001)$ and exceeded the recommended level of 0.70 (Chin, 1998). Second, the composite reliabilities, which indicate the internal consistency of the measurement model, ranged from 0.88 to 0.96 , exceeding the recommended cutoff level of 0.80 (Fornell \& Larcker, 1981). Third, the AVE ranged from 0.72 to 0.90 , exceeding the threshold value of 0.50 (Fornell \& Larcker, 1981).

The discriminant validity of the measurement model was examined by comparing the correlation between constructs and square root of AVE for each construct (Fornell \& Larcker, 1981). Table 2 indicates that the correlation of each construct was lower than the square root of AVE, confirming that the constructs exhibited discriminant validity. In summary, the measurement model exhibited adequate reliability as well as both convergent and discriminant validity. 
Table 3. Results of confirmatory factor analysis for the measurement model

\begin{tabular}{|c|c|c|c|c|c|}
\hline Constructs & Items & $\begin{array}{l}\text { Factor } \\
\text { loading }\end{array}$ & $\begin{array}{c}\text { Cronbach's } \\
\text { alpha }\end{array}$ & $\begin{array}{l}\text { Composite } \\
\text { reliability }\end{array}$ & $\begin{array}{l}\text { Variance } \\
\text { extracted }\end{array}$ \\
\hline & tas 1 & 0.81 & \multirow{5}{*}{ N/A } & \multirow{5}{*}{ N/A } & \multirow{5}{*}{$\mathrm{N} / \mathrm{A}$} \\
\hline Task & $\operatorname{tas} 2$ & 0.79 & & & \\
\hline Characteristics(TASs) & $\operatorname{tas} 3$ & 0.79 & & & \\
\hline & $\operatorname{tas} 4$ & 0.89 & & & \\
\hline & tec 1 & 0.86 & & & \\
\hline Technology & tec 2 & 0.73 & \multirow{3}{*}{ N/A } & \multirow{3}{*}{ N/A } & \multirow{3}{*}{ N/A } \\
\hline Characteristics(TECs) & tec 3 & 0.85 & & & \\
\hline \multirow{4}{*}{$\begin{array}{c}\text { Task-Technology } \\
\text { Fit(TTF) }\end{array}$} & tec 4 & 0.81 & & & \\
\hline & $\mathrm{ttfl}$ & 0.91 & \multirow{3}{*}{0.89} & \multirow{3}{*}{0.93} & \multirow{3}{*}{0.82} \\
\hline & $\mathrm{ttf} 2$ & 0.93 & & & \\
\hline & $\mathrm{ttf3}$ & 0.88 & & & \\
\hline \multirow{4}{*}{$\begin{array}{c}\text { Performance } \\
\text { Expectancy(PE) }\end{array}$} & pe1 & 0.93 & \multirow{4}{*}{0.94} & \multirow{4}{*}{0.96} & \multirow{3}{*}{0.89} \\
\hline & pe2 & 0.95 & & & \\
\hline & pe3 & 0.94 & & & \\
\hline & ee1 & 0.90 & & & \\
\hline Effort & ee2 & 0.91 & \multirow{3}{*}{0.92} & \multirow{3}{*}{0.94} & \multirow{3}{*}{0.80} \\
\hline \multirow[t]{3}{*}{ Expectancy(EE) } & ee3 & 0.92 & & & \\
\hline & ee4 & 0.86 & & & \\
\hline & si1 & 0.93 & \multirow{3}{*}{0.94} & \multirow{3}{*}{0.96} & \multirow{3}{*}{0.90} \\
\hline Social Influence(SI) & si2 & 0.96 & & & \\
\hline \multirow{4}{*}{$\begin{array}{c}\text { Facilitating } \\
\text { Conditions(FCs) }\end{array}$} & si3 & 0.95 & & & \\
\hline & $\mathrm{fc} 1$ & 0.86 & \multirow{3}{*}{0.80} & \multirow{3}{*}{0.88} & \multirow{3}{*}{0.72} \\
\hline & $\mathrm{fc} 2$ & 0.89 & & & \\
\hline & $\mathrm{fc} 3$ & 0.78 & & & \\
\hline \multirow{3}{*}{$\begin{array}{c}\text { Hedonic } \\
\text { Motivation(HM) }\end{array}$} & $\mathrm{hm} 1$ & 0.94 & \multirow{3}{*}{0.92} & \multirow{3}{*}{0.95} & \multirow{3}{*}{0.85} \\
\hline & $\mathrm{hm} 2$ & 0.92 & & & \\
\hline & $\mathrm{hm} 3$ & 0.91 & & & \\
\hline
\end{tabular}





\begin{tabular}{cccccc}
\hline & hb1 & 0.93 & & & \\
Habit(HB) & hb2 & 0.89 & 0.90 & 0.94 & 0.84 \\
& hb3 & 0.93 & & & \\
Behavioral & bi1 & 0.92 & & & \\
Intention(BI) & bi2 & 0.95 & 0.90 & 0.94 & 0.83 \\
& bi3 & 0.86 & & & \\
\hline
\end{tabular}

Note: TASs and TECs are formative constructs; thus, their values are not available (N/A).

\subsection{Structural Model and Hypothesis Testing}

The SmartPLS 2.0 analysis of hypothesis and construct relationships was based on the examination of standardized paths. The path significance levels were estimated through the bootstrap resampling method with 500 iterations suggested by Goodhue, Lewis, and Thompson (2007). The results are summarized in Figure 2. For the overall model fit of PLS path modeling, a goodness-of-fit was suggested (Tenenhaus, Vinzi, Chatelin, \& Lauro, 2005), which was defined as the geometric mean of the average communality and the average R2 (for endogenous constructs). The observed GoF was 0.68 , which exceeded the large effect sizes criterion of 0.36 (Wetzels, Odekerken-Schröder, \& van Oppen, 2009, p. 187).

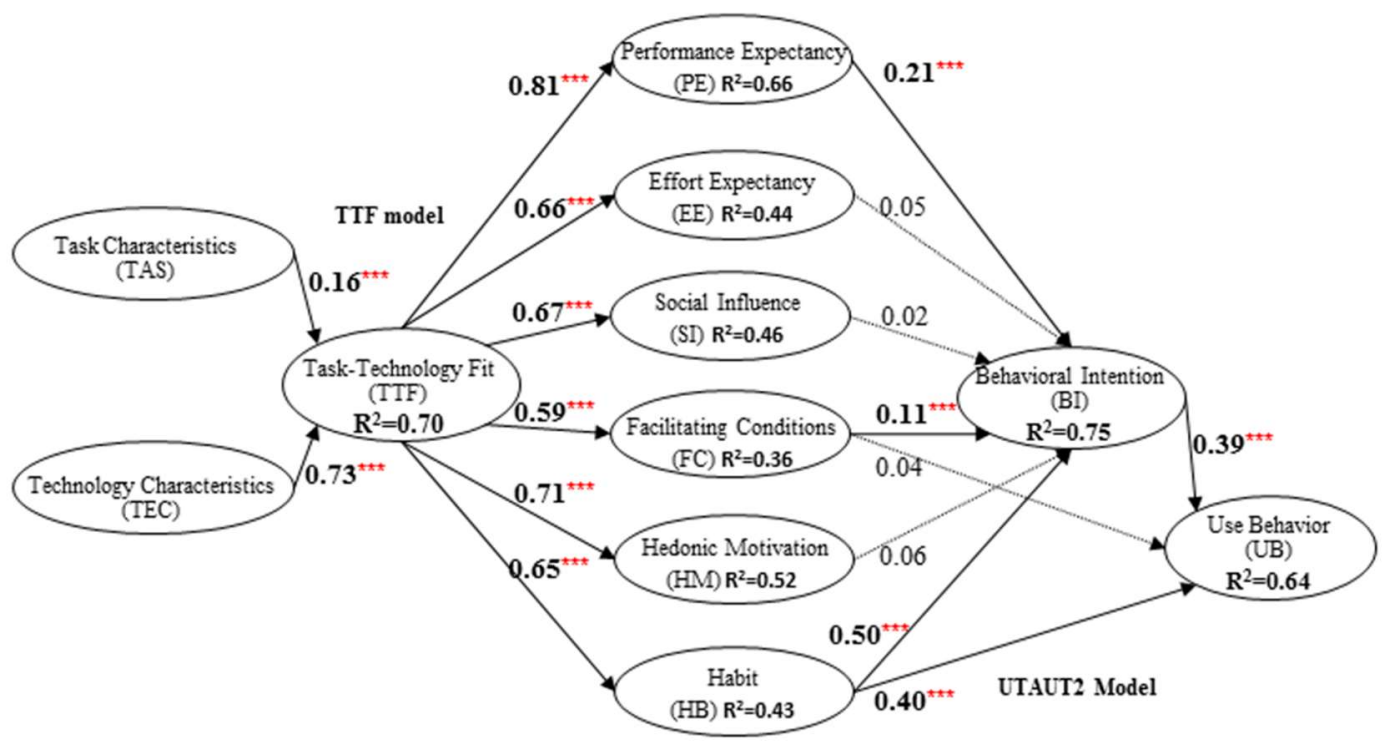

Figure 2. Results of SmartPLS 2.0 path analysis (Hypotheses in bold were supported and ${ }^{* * *}$ represent $\left.p<.001\right)$. 

Except for the hypothesized path between EE and BI (H6), SI and BI (H7), FCs and UB (H8b), and HM and BI (H9), all the other paths in the model were significant $(\mathrm{p}<.001)$ in the anticipated direction.

In the final stage of analysis, we conducted a Harman's single factor test to assess the degree to which common method variance (CMV) may inflate or attenuate the observed correlations between measures. Following Podsakoff and Organ's (1986) recommendation, we forced all the study variables into a factor analysis to determine whether a single factor can account for all the variance in the data and whether the subsequent model would fit the data. Results of the unrotated factor solution indicated that CMV was not a major concern in our data, because the single factor model did not fit the data well.

\section{DISCUSSION}

The theoretical model presented is unique because it synergistically combines TTF and UTAUT2 in evaluating the decision to adopt EWs. The interpretation of the results based on the empirical findings is discussed further in the subsequent sections.

\subsection{Task-Technology Fit}

Despite the fact that job searching on EWs is a relatively general concept in Taiwan and people are fully aware of the various job searching tasks that can be conducted through this service, industrious EWs have continuously developed friendly search interfaces with pooled, valued job postings in the past 20 years through third-party e-recruiting providers to improve their future when they are confronted with tough competition from social networking websites. This explains the limited effect of TASs on TTF, compared with the TECs. However, EWs are gaining recognition as a useful job searching service, and the research model in this study explained $70 \%$ of the variation in TTF. This is consistent with results from similar studies (Oliveira, Faria, Thomas, \& Popovič, 2014).

Additionally, according to the TPC, we reproduced the relationship between TTF and the precursors (beliefs or affect) of use. Our empirical findings support the assumption that TTF strongly influences the precursors (PE, EE, SI, FCs, HM, and HB) of use.

\subsection{UTAUT2}

The results of our study also indicated that the UTAUT2 model obtained improved explanation power over the UTAUT model displayed in Figure 2. This is consistent with the comparison results of a 7-TAMs (including UTAUT and UTAUT2 models) study (RondanCataluña, Arenas-Gaitán, \& Ramírez-Correa, 2015).

PE and its related construct "perceived usefulness" have been significant in most studies performed using the UTAUT or UTAUT2 models (e.g., Baptista \& Oliveira, 2015; Oliveira et al., 2014; Pascual-Miguel, Agudo-Peregrina, \& Chaparro-Peláez, 2015) or any related models 
involving online recruitment (Laumer et al., 2010; Lin, 2010; Tong, 2009). Our study also revealed that $\mathrm{PE}$ is a significant antecedent for adopting an EW. Our results indicated the differing characteristics (regardless of gender, age, level of education, search intensity, and number of EW used) of job seekers who can expect to increase their chances of attaining jobs more easily and quickly.

The insignificance of EE in our study differs from the results of other IS adoption studies (Venkatesh et al., 2003; Venkatesh et al., 2012), which have determined that EE or ease of use is a significant antecedent of intention to use a daily IS. However, EWs are only used when a person applies for a job, as suggested by relevant studies (Laumer et al., 2010; Tong, 2009). The findings of this study also confirm that EE exhibits an insignificant effect on BI to use EWs.

However, the relationship between SI and BI was determined to be insignificant. Several prior studies have indicated the relationship between SI and BI to be inconsistent and weak (e.g., Baptista \& Oliveira, 2015; Laumer et al., 2010; Oliveira et al., 2014), which is further supported by the current study. This might lead to a conclusion that involves individual task-specific selfesteem or financial need (Blau, 1994), thereby influencing job seekers not to disclose unemployment anxiety, influence people, or adopt their opinions.

The infrastructure support for using a system (FCs) is another critical antecedent of erecruiting system adoption, as in the UTAUT (Venkatesh et al., 2003) and UTAUT2 (Venkatesh et al., 2012). FCs were observed to significantly affect BI, but not significantly affect UB. This is similar to what has been reported by earlier studies (Baptista \& Oliveira, 2015), but also contradicts the results of other studies (Oliveira et al., 2014; Yu, 2012). We believe that people in Taiwan do not expect to use EWs even if they are effective and have the organizational and technical infrastructure support to help them use job searching services; people in Taiwan therefore do not consider EWs to be very crucial.

Our results do not reveal any effects of HM on BI. This is consistent with what was reported in an earlier study (Arenas-Gaitán, Peral-Peral, \& Ramón-Jerónimo, 2015), but contradicts the results of other studies (Baptista \& Oliveira., 2015; Pascual-Miguel et al., 2015). In job seeker contexts, unlike consumer contexts, users are unhappy or incompetent at their old jobs or are searching for employment, and may also be facing unemployment without financial security. We believe that HM cannot dominate job seeker adoption decisions.

HB was determined to be the most significant antecedent of BI and UB in EWs. Earlier studies have reported HB to be a major predictor of intention (Venkatesh \& Agarwal, 2006). Our research model validates the relationships among $\mathrm{HB}, \mathrm{BI}$, and UB, which is consistent with an earlier study (Baptista \& Oliveira, 2015). Therefore, we believe that stronger HB generates a stored intention and subsequently influences behavior. 


\section{CONCLUSION}

The present study quantified and identified determinants of job seekers' acceptance and use of EWs by using an aggregate model that applied TTF and UTAUT2 theory. The present study revealed that the most crucial constructs explaining EW adoption are HB, BI, PE, and FCs.

In addition to $\mathrm{PE}$ and FCs, which are considered major predictors of intention to use EWs, a substantial contribution of this study was that job seekers' HB was also verified to be a major predictor of intention and usage in EWs involving web-based technology and occasional usage. Thus, the past behavior of job seekers exerts a substantial effect on their assessment of whether to continue the behavior in the future. The application of TTF and the inclusion of individual characteristics is a critical juncture in understanding the use of EWs. When job seekers perceive their task (searching the posts online) to fit the technology (EWs), they recognize the value of using the technology and use it habitually. This indicates that achieving greater EW adoption requires improving the TTF between the job searching task and EW technology 



\section{References}

[1] Arenas-Gaitán, J., Peral-Peral, B., \& Ramón-Jerónimo, M. A. (2015). Elderly and Internet banking: An application of UTAUT2. Journal of Internet Banking and Commerce, 20(1), 1-23.

[2] Baptista, G., \& Oliveira, T. (2015) Understanding mobile banking: The unified theory of acceptance and use of technology combined with cultural moderators. Computers in Human Behavior, 50, 418-430.

[3] Bergkvist, L. (2015). Appropriate use of single-item measures is here to stay. Marketing Letters, 26(3), 245-255.

[4] Blau, G. (1994). Testing a two-dimensional measure of job search behavior. Organizational Behavior and Human Decision Processes, 59(2), 288-312.

[5] Brenčič, V. (2014). Search online: Evidence from acquisition of information on online employment websites and resume banks. Journal of Economic Psychology, 42, 112125.

[6] Brenčič, V., \& Norris, J. B. (2009). Employers' online search: An empirical analysis. Industrial Relations, 48(4), 684-709.

[7] Brown, S. A., \& Venkatesh, V. (2005). Model of adoption of technology in households: A baseline model test and extension incorporating household life cycle. MIS Quarterly, 29(3) 399-426.

[8] Brown, S. A., Venkatesh, V., \& Hoehle, H. (2015). Technology adoption decisions in the household: A seven-model comparison. Journal of the Association for Information Science \& Technology, 66(9), 1933-1949.

[9] Chin, W. W. (1998). Commentary: Issues and opinion on structural equation modeling. MIS Quarterly, 22(1), vii-xvi.

[10]Diamantopoulos, A., \& Siguaw, J. A. (2006). Formative versus reflective indicators in organizational measure development: A comparison and empirical illustration. British Journal of Management, 17(4), 263-282.

[11]Dishaw, M. T., \& Strong, D. M. (1999). Extending the technology acceptance model with task-technology fit constructs. Information \& Management, 36(1), 9-21. 
[12]Fornell, C., \& Larcker, D. F. (1981). Evaluating structural equation models with unobservable variables and measurement error. Journal of Marketing Research, 18(1), $39-50$.

[13] Goodhue, D. L., Lewis, W., \& Thompson, R. (2007). Research note-Statistical power in analyzing interaction effects: Questioning the advantage of PLS with product indicators. Information Systems Research, 18(2), 211-227.

[14]Goodhue, D. L., \& Thompson, R. L. (1995). Task-technology fit and individual performance. MIS Quarterly, 19(2), 213-236.

[15]Hair, J. F., Hult, G. T. M., Ringle, C. M., \& Sarstedt, M. (2013). A primer on partial least squares structural equation modeling (PLS-SEM). Los Angeles, CA: SAGE Publications Inc.

[16]Jansen, B. J., Jansen, K. J., \& Spink, A. (2005). Using the web to look for work: Implications for online job seeking and recruiting. Internet Research, 15(1), 49-66.

[17]Kim, D., Chun, H., Kwak, Y., \& Nam, Y. (2014). The employment of dialogic principles in website, Facebook, and Twitter platforms of environmental nonprofit organizations. Social Science Computer Review, 32, 590-605.

[18]Kim, S. S., \& Malhotra, N. K. (2005). A longitudinal model of continued IS use: An integrative view of four mechanisms underlying post-adoption phenomena. Management Science, 51(5), 741-755.

[19]Laumer, S., Eckhardt, A., \& Trunk, N. (2010). Do as your parents say? Analyzing IT adoption influencing factors for full and under age applicants. Information Systems Frontiers, 12(2), 169-183.

[20]Limayem, M., Hirt, S. G., \& Cheung, C. M. K. (2007). How habit limits the predictive power of intentions: The case of IS continuance. MIS Quarterly, 31(4), 705-737.

[21]Lin, H. F. (2010). Applicability of the extended theory of planned behavior in predicting job seeker intentions to use job-search websites. International Journal of Selection and Assessment, 18, 64-74.

[22]Lu, H. P., \& Yang, Y. W. (2014). Toward an understanding of the behavioral intention to use a social networking site: An extension of task-technology fit to social-technology fit. Computers in Human Behavior, 34, 323-332. 
[23]Maurer, S. D., \& Liu, Y. (2007). Developing effective E-recruiting web sites: Insights for managers from marketers. Business Horizons, 50, 305-314.

[24] Negahban, A., \& Chung, C. H. (2014). Discovering determinants of users perception of mobile device functionality fit. Computers in Human Behavior, 35, 75-84.

[25]Nunnally, J. C. (1978). Psychometric theory. New York: Mcgraw-Hill.

[26] Nikolaou, I. (2014). Social networking web sites in job search and employee recruitment. International Journal of Selection and Assessment, 22(2), 179-189.

[27] Oliveira, T., Faria, M., Thomas, M. A., \& Popovič, A. (2014). Extending the understanding of mobile banking adoption: When UTAUT meets TTF and ITM. International Journal of Information Management, 34(5), 689-703.

[28]Pascual-Miguel, F. J., Agudo-Peregrina, Á. F., \& Chaparro-Peláez, J. (2015). Influences of gender and product type on online purchasing. Journal of Business Research, 68(7), $1550-1556$.

[29]Podsakoff, P. M., \& Organ, D. W. (1986). Self-reports in organizational research: Problems and prospects. Journal of Management, 12(4), 531-544.

[30]Polat, E. \& Gunay, S. (2015). The comparison of partial least squares regression, principal component regression and ridge regression with multiple linear regression for predicting PM10 concentration level based on meteorological parameters. Journal of Data Science, 13(2), 663-692.

[31]Rondan-Cataluña, F. J., Arenas-Gaitán, J., \& Ramírez-Correa, P. E. (2015). A comparison of the different versions of popular technology acceptance models. Kybernetes, 44(5), 788-805.

[32] Selden, S., \& Orenstein, J. (2011). Government E-recruiting web sites: The influence of E-recruitment content and usability on recruiting and hiring outcomes in US state governments. International Journal of Selection and Assessment, 19, 31-40.

[33]Tenenhaus, M., Vinzia, V. E., Chatelin,Y. M., \& Lauro, C. (2005). PLS path modeling. Computational Statistics \& Data Analysis, 48(1), 159-205.

[34]Tong, D. Y. K. (2009). A study of E-recruitment technology adoption in Malaysia. Industrial Management \& Data Systems, 109(2), 281-300. 

[35]Venkatesh, V., \& Agarwal, R. (2006). Turning visitors into customers: A usabilitycentric perspective on purchase behavior in electronic channels. Management Science, 52(3), 367-382.

[36]Venkatesh, V., \& Davis, F. D. (2000). A theoretical extension of the technology acceptance model: Four longitudinal field studies. Management Science, 46(2), 186204.

[37]Venkatesh, V., Morris, M. G., Davis, G. B., \& Davis, F. D. (2003). User acceptance of information technology: Toward a unified view. MIS Quarterly, 27(3), 425-478.

[38] Venkatesh, V., Thong, J. Y. L., \& Xu, X. (2012). Consumer acceptance and use of information technology: Extending the unified theory of acceptance and use of technology. MIS Quarterly, 36(1), 157-178.

[39] Wetzels, M., Odekerken-Schröder, G., \& Van Oppen, C. (2009). Using PLS path modeling for assessing hierarchical construct models: Guidelines and empirical illustration. MIS Quarterly, 33(1), 177-195.

[40]Yu, C. S. (2012). Factors affecting individuals to adopt mobile banking: Empirical evidence from the UTAUT model. Journal of Electronic Commerce Research, 13(2), $104-121$

\footnotetext{
${ }^{1}$ Kuo-Yu Huang (corresponding author)

Graduate Institute of Business Administration, College of Management, Fu Jen Catholic University,

No. 510 Zhongzheng Rd, Xinzhuang Dist., New Taipei City, 242 Taiwan, ROC.

Tel: $886-2-85902848$

Fax: 886-2-85902836

E-mail: ca0622@gmail.com

${ }^{2}$ Yea-Ru Chuang

Department of Information Management, College of Management, Fu Jen Catholic University,

No. 510 Zhongzheng Rd, Xinzhuang Dist., New Taipei City, 242 Taiwan, ROC.

E-mail: 013486@mail.fju.edu.tw
} 